\title{
Green consumption and relative preferences in a vertically differentiated international oligopoly*
}

\author{
Giulia Ceccantoni†, Ornella Tarola
}

March 12, 2018

\begin{abstract}
We consider an open to trade two-country model with two vertically differentiated goods and relative preferences in consumption. These preferences are such that consumers obtain satisfaction from their own consumption in relation to the consumption of the others. Product differentiation is along an environmental quality dimension and countries are asymmetric in average income. Analyzing the equilibrium configuration, we find that, when relative preferences are relegated to the poorer country producing the brown good, the process of trade liberalization can favor the polluting firm, while penalizing the green rival. In these circumstances, trade liberalization can be environmentally detrimental. At the opposite, trade liberalization always favors the green producer when relative preferences are observed in both countries, with possibly positive effects on global emissions.
\end{abstract}

Keywords: relative preferences; green consumption; vertical differentiation; international oligopoly; trade liberalization.

JEL Classification Numbers: D11; F18; L13.

\footnotetext{
${ }^{*}$ We would like to thank for useful discussions Nada Ben Elhadj, Jean Gabszewicz, Efthymia Kyriakopoulou, Alessandro Tampieri and two anonymous referees for fruitful comments. The usual disclaimer applies.

${ }^{\dagger}$ MEMOTEF, University of Rome, La sapienza Via Del Castro Laurenziano 9, Roma, 00161. Email: giulia.ceccantoni@uniroma1.it

${ }^{\ddagger}$ DISSE, University of Rome, La Sapienza Piazzale Aldo Moro, 5, Rome, 00100, Tel: +39 0649910253, Fax: +39 0649690326. Email: ornella.tarola@uniroma1.it

${ }^{\S}$ Corresponding Author: CREA, University of Luxembourg. Address: 162A, avenue de la Faiencerie, L-1511, Luxembourg. Tel: (+352) 466644 6464; Fax (+352) 4666446341 email: skerdilajda.zanaj@uni.lu
} 


\section{Introduction}

"There is strong agreement across the EU about the ethics of environmentallyfriendly products: $95 \%$ of respondents agreed that using environmentally friendly products is 'the right thing to do', $91 \%$ agreed that buying environmentally-friendly products sets a good example and $80 \%$ agreed that their family and friends would think it was a good thing if they used environmentally-friendly products." Eurobarometer, 2013 (italics added by the authors).

Since the famous treatise by Veblen (1899), conspicuous practices intended as means to satisfy craving for power or social approval have been largely observed among consumers. While, for a long time, luxurious cars, expensive wine and apparel have been considered the key drivers for high social status, more recent approaches have identified further conspicuous goods for a relative position in the social community. For example, the environmental degradation of the planet has generated increasing concerns among people who are currently aware of the devastating effects of global pollution on public health. Protecting environment is viewed as a way to preserve the future of human beings and to care for relatives, peers and friends. As a natural by-product of this awareness, environmentally friendly products have been introduced in the set of conspicuous goods: green consumption is nowadays a byword for good citizenship and green products are conspicuous means to get the status of good citizens.

The conspicuous content of green consumption opens the door to two considerations.

First, the social reward for environmental protection shall be wider the more conspicuous are the goods. Whenever the environmental quality gap between a green variant and an ordinary product is not extremely relevant, the contribution to environmental protection, and thus to the social community, coming from green consumption is not significant. In this circumstance, green consumers do not distinguish themselves from dirty buyers and thus do not obtain the visible status of socially worthy citizens. It is as if the product's ranking along the environmental quality ladder would determine the consumers' ranking along the social ladder. In 2007, the New York Times cited the main reasons why Toyota Prius owners bought their hybrid cars. It emerged that the buyers had "only a basic understanding of environmental issues or the ecological benefits of HEVs (hybrid electric vehicles)" and they purchased only because "it shows the world that its owner cares" (Heffner et al 2007, p. 409).

Second, the environmental concern determining the conspicuous dimension of green good is mainly country specific. Individuals living in the same neighborhood or the same region and sustained by a same level of average income may share a set of shared values, behaviours and beliefs (Dietz et al, 2005; Steg and de Groot, 2012) that determine a common consciousness about the environmental issues as well as about the socially appreciated consumption attitudes/choices (Litina et al., 2016). ${ }^{1}$ Nonetheless, countries are more and more involved in international agreements which liberalize trade and reduce the costs of export/import. As a consequence of this trade liberalization

\footnotetext{
${ }^{1}$ Ultimately, these shared values provide social mechanisms which sanction any deviation from the set of appreciated attitudes and reward a compliant behavior. Additionally, individual perceptions about the causes of pollution
} 
process, consumers living in different country, with heterogenous income, culture and beliefs, get familiar with goods that they would not know in absence of trade. ${ }^{2}$

These considerations generate some questions that we try to give an answer in this paper. How the conspicuous dimension of green consumption affect the equilibrium configuration of the market? Countries differ not only in terms of culture and values but also in terms of income levels. Does the worldwide distribution of environmental consciousness play a role in curbing global emissions? What is the contribution, if any, of trade liberalization to the environment when taking into account that green goods can be perceived as conspicuous products?

We define a partial equilibrium model with two asymmetric countries as in Cabrales and Motta (2001) and two vertically differentiated goods where the green good is the high quality good. ${ }^{3}$ Consumers in each country are heterogenous with respect to their willingness to pay for quality. Countries are asymmetric in terms of average income. The richer country produces a clean good while the latter, the poorer, specializes in the production of a brown good. ${ }^{4}$ Each country is populated by a firm. Each firm exports its product thereby facing an iceberg cost, which is lower the more liberalized trade is. Introducing this cost in the model enables to consider how the profitability to produce green versus brown goods changes with the process of trade liberalization.

When defining consumption behaviour in a country, we do not depart from the well-known concept of homo economicus, a rational and self-interested agent who traditionally maximizes his/her utility. Still, we reconcile this traditional approach with the idea that human beings are (at least partially) affected by social interaction and driven in their behaviour by some country specific social values. Thus, when consuming conspicuous goods, they obtain social benefits or incur social stigma, behind the material needs which are typically met. In line with this, we assume that goods are valued along two dimensions: their intrinsic quality and their social component. The former, in accordance with the traditional model of vertical differentiation à la Mussa and Rosen, is such that the absolute quality of a variant determines its utility. So, the green good is the high quality variant along the quality ladder since it dominates the competing and low-quality alternative from an environmental viewpoint. The latter induces consumers to value a variant depending on its relative environmental quality, namely the quality gap between the variant itself and the alternative one: this gap determines the social value of the good and thus fixes the status of her buyer along a social ladder. We formalize this social component through relative preferences and, borrowing some ingredients from Ben Elhadj and Tarola (2015), we nest them in a vertically differentiated

seem quite different among people living in rich and poor countries as reported by The Health of the Planet Survey (Dunlap and Metig, 1995). People living in rich countries show much more awareness about the role of their individual green versus brown consumption on pollution in the country of residence: feeling responsible w.r.t. environment belongs to a set of values arising after essential needs have been satisfied.

${ }^{2}$ For a dynamic analysis, with vertically differentiated goods, see Gabszewicz et al, 2017, who study how consumption habits evolve when countries open to trade.

${ }^{3}$ A good survey of the industrial organisation models nested with international trade is Krugman (1989).

${ }^{4}$ This assumption is in line with the traditional view of a North-South model of production where dirty productions are relegated in less developed countries, the green ones being rather in the more advanced groups of nations (see for instance Copeland and Taylor 1994 and Fajgebaum et al, 2011). 
market. ${ }^{5}$

Accordingly, under the assumption of country-specific relative preferences, we characterize the equilibrium configuration of the oligopoly. In particular, we first describe the role of relative preferences by comparing this equilibrium with a baseline where relative preferences are absent. Second, under country-specific relative preferences, we study the effect of trade liberalization on the equilibrium configuration thereby evaluating the role of trade liberalization.

We consider different scenarios. After presenting the related literature (Section 2), we provide the presentation of the model in Section 3 and the description of the setup without relative preferences in Section 4. In Section 5, we characterize the scenario where consumers in both countries display relative preferences. Then, in Section 6 we assume that relative preferences emerge only in one country. We conclude in Section 7.

We find that relative preferences in both countries never reduce the optimal quantity of goods and the corresponding trade exchanges w.r.t. the baseline. Moreover, the twofold goal of increasing the production of green good at expense of the brown one and curbing global emissions is reached whenever trade liberalization is sufficiently significant. This shows that while some results could be true in a closed economy, they can cease to be valid in a more realistic world of open trading areas.

More relevant, increasing trade liberalization can reduce global emissions only in the case when both areas attribute a social content to green consumption. By contrast, trade liberalization is always environment detrimental when relative preferences are observed in the poorer country.

\section{Related literature}

Our paper locates in the existing literature that analyses conspicuous consumption and the corresponding role played by the social content of preferences. More specifically, our modelling strategy is inspired by the empirical literature on conspicuous green consumption and social status. Sexton and Sexton (2014) test for the presence of a conspicuous conservation effect in vehicle purchase decisions and estimate the willingness to pay for the "green halo" generated by signaling green type. They find that "green" cars are more valuable in communities with a strong green ethos than in communities with greater heterogeneity in attitudes toward the environment. Welsch and Kühling (2009) using a panel data for Germany find evidence that the green consumption of reference persons plays a significant role on whether individuals install residential solar energy equipment or subscribe to green-electricity programs. It seems indeed that when buying environmentally-friendly products agents feel to set a good example for their peers and that their family and friends would

\footnotetext{
${ }^{5}$ Relative preferences capture the idea that consumers obtains satisfaction from their own consumption in relation to the consumption of the others. Specific relative preferences have been considered for example by Akerlof (1997). In his paper, the satisfaction of a consumer increases with the difference between the personal status and others' status. Alexopoulos and Sapp (2006) and Riechmann (2006) analyze relative preferences from the point of view of firms. They are also labeled 'other-regarding preferences'.
} 
appreciate back if they used environmentally-friendly product. ${ }^{6}$ Alpizar and Gsottbauer (2015) present a framed field experiment on the role of reputation as a driver of a recycling behaviour. They find that reputation plays a role in promoting green efforts. Interestingly, the willingness to avoid shame generated by a bad behaviour is stronger than the one to acquire gratitude or good reputation.

We believe that this phenomenon can be modelled in a parsimonious way using related preferences to study market outcomes, as we did in this paper. ${ }^{7}$

Our analysis complements the theoretical literature on social norms and pro-environmental behavior (see e.g., Stern, 2000; Brekke et al., 2003) thereby contributing to the debate on the impact of environmentally friendly behavior on market equilibrium (Conrad, 2005; Lombardini and Riipinen, 2005, Eriksson, 2004; Garcia-Gallego and Georgantzs, 2009; Moraga-Gonzalez and Padron-Fumero, 2002; Nyborg et al., 2006; Rodriguez-Ibeas 2007). These papers show that consumers are partially driven in their consumption choice by some social norms which define rules of interactions among individuals (Hage et al. 2009; Ostrom, 2000; Carlsson et al., 2010; Deltas et al., 2013; Abbott et al. 2013; Mantovani et al. 2017). These norms are enforced by interiorized feelings and/or cultural beliefs and, when concerned with environmental issues, state that green consumption is a habit displayed by good citizens. Accordingly, while buying clean products, people feel to comply with a norm of worthy citizenship and, thus, obtain a social/psychological benefit of social approval and self-esteem. Along the same rationale, they suffer a social stigma when purchasing dirty products. ${ }^{8}$

From a methodology point of view, the existing literature has already treated open economy versions of the vertically differentiated duopoly framework. For instance, Motta and Thisse (1993) extend the vertical differentiation model to two countries with two firms each in order to analyse the effects of environmental quality standards in autarky and free trade. Herguera et al. (2000) study the effect of quantity restrictions on the quality choice in a vertically differentiated model. At the best of our knowledge, we are the first to use relative preferences, along a quality dimension, to capture the social content of green consumption in an open economy version of the vertical differentiated duopoly.

Last, even though we use a very different setting, our paper is related to existing literature on (i) quality and international trade and (ii) pollution and trade liberalization. Quality and

\footnotetext{
${ }^{6}$ Torgler and García-Valiňas (2007) in a different but close perspective stress the role of trust and membership in promoting pro-environmental behaviour. See also Van der Bergh (2008) for an empirical analysis on potential psychological determinants of a pro-environmental behavior.

${ }^{7}$ Consipicous consumption that translates into peer comparison appears also in other consumption decisions rather than environmental-friendly goods. For instance, Fliessbach et al. (2007), and Dohmen et al. (2011), using brain images, find evidence that the well-being of individuals depends not only on their income but also by the comparison of their income to that of others. Peer comparison affects retirements plans (Beshears et al. 2015), financial decisions (Bursztyn et al. 2014 ) or housing choices (Schunemann and Trimborn, 2017).

${ }^{8}$ In line with this argument, Owen and Videras $(2006,2007)$ and Videras et al. (2012) argue that individuals who are more willing to behave according to civic and cultural norms and have more social ties are also more willing to protect a public good, namely, the natural environment, while Brekke et al. (2003, 2010) and Czajkowski et al. (2015) show that self image is central to recycling behavior. Cecere at al. (2014) claim that altruistic motives induce people to buy green products so that green behaviour is not always reinforced by social norms.
} 
trade literature has considerably expanded since the seminal paper by Linder (1961) showing that product quality matters in the trade patterns among trading partners (Hummels and Klenow, 2005; Verhoogen, 2008; Khandelwal, 2010; Hallak and Schott, 2011; Baldwin and Harrigan, 2011; Fajgebaum et al, 2011). Existing papers have analysed how trade liberalization affects quality choice when countries are asymmetric (Cabrales and Motta, 2001) or the role of income effects in the quality choice in presence of international trade with non homothetic preferences (Picard and Tampieri, 2016).

The literature over the role trade plays in determining environmental outcomes is large and often with contradicting results. The pollution haven hypothesis suggests that relatively low income countries will be made dirtier with trade. Whereas, the factor endowment theory, suggests that trade will induce the dirty capital-intensive processes to locate to the relatively capital abundant rich countries. Empirical findings are also mixed (for instance Antweiler et al, 2001; Copeland and Taylor 2003).

At the best of our knowledge, we are the first to bring together key factors as the social content of consumption, product quality and trade in a unique theoretical setup. More precisely, we bring a setting that uses relative preferences along a quality dimension to capture the social content of green consumption in an international trade model with the purpose of analysing the effect of trade liberalization on prices, firms' profits and pollution.

\section{The Model}

Consider a two-country model with two vertically differentiated goods along an environmental quality dimension. Each country is populated by a single firm. We label Green and Brown each country and the corresponding firm within the country. The Green (resp. Brown) firm produces the high (resp. low) environmental variant $q_{G}\left(\right.$ resp. $\left.q_{B}\right) .{ }^{9}$ The range of quality is in the interval $[\bar{q}, \underline{q}]$ where $\bar{q}$ is the highest quality level that is technologically feasible and $\underline{q}>0$ is the lowest one. Each firm can serve both countries. When serving the foreign market, it incurs iceberg trade $\operatorname{costs} \tau, 1 \geq \tau \geq 0$. Trade costs are related not only to the geographical distance between countries but also and mainly to cultural barriers, tariffs and administrative costs. This distance determines a gap between the quantity produced to serve the foreign market and the one actually arrived at destination. More specifically, from the firms viewpoint, this distance creates a gap between the quantity produced to serve the foreign market and the one generating profits. When $\tau$ is closer to 1 , trade costs are relatively low and the quantity produced to serve the foreign market is similar to the one determining profits. When $\tau$ is close to 0 , then trade barriers erode a significant amount of quantity targeted to the foreign market with a negative effect on profits, ceteris paribus.

As for the demand side, in each country, consumers are characterized by their willingness to pay

\footnotetext{
${ }^{9}$ In line with the traditional approach in vertical differentiation (Mussa and Rosen, 1978 and Gabszewicz and Thisse, 1979), we interprete $q_{i}$ as the quality of variant $i$. We assume that it is exogenously given. Of course, there exist constributions which keep this traditional intepretation but endogeneize the variant. See for example Rodriguez-Ibeas (2007) and Andre et al. (2009).
} 
for environmental quality indexed by $\theta$, uniformly distributed over the interval $\left[0, \Theta_{i}\right], i=G, B$. Parameter $\Theta_{i}$ denotes the highest willingness to pay for quality in country $i$. We assume that $\Theta_{G}>\Theta_{B}$. Thus, the average willingness to pay in country $G$ is higher than in country $B$ : consumers in the two countries differ in their taste for quality and this difference can rest on differences in income (as in Gabszewicz and Thisse, 1979). Accordingly, the richer country produces the green good, while the poorer country produces the brown one. ${ }^{10}$ This is a similar assumption to Flam and Helpman (1987) or Murphy and Shleifer (1997) who argue that the high quality good is produced in the richer countries whereas the low quality good is produced in the poorer ones. ${ }^{11}$

\section{The baseline scenario: absence of relative preferences}

We first consider a closed economy scenario where, in absence of trade, a monopoly in country $i$ only serves the domestic market $i, i=G, B$. Consumers display the same preferences with respect to variants, so that their indirect utility function $U_{i}(\theta)$ writes as

$$
U_{i}(\theta)= \begin{cases}\theta q_{G}-p_{G} & \text { if she buys G } \\ \theta q_{B}-p_{B} & \text { if she buys B } \\ 0 & \text { otherwise }\end{cases}
$$

In this case, the indifferent consumer between buying variant $i$ and not buying at all is $\hat{\theta}_{i}=\frac{p_{i}}{q_{i}}$ with $i=G, B$. Then, it is immediate that, at equilibrium, price and quantity $p_{i}^{A}$ and $q_{i}^{A}$ are:

$$
\begin{aligned}
p_{G}^{A} & =\frac{1}{2} q_{G} \Theta_{G} \text { and } p_{B}^{A}=\frac{1}{2} q_{B} \Theta_{B} \\
x_{G}^{A} & =\frac{1}{2} \Theta_{G} \text { and } x_{B}^{A}=\frac{1}{2} \Theta_{B},
\end{aligned}
$$

where the subscript $A$ stands for autarky. Finally, we define pollution damage as:

$$
E^{A}=E_{G}^{A}+E_{B}^{A}
$$

with $E_{G}=\alpha x_{i}, \alpha \in(0,1)$ and $E_{B}=x_{B} \cdot{ }^{12}$ Accordingly, polluting emissions in country $G$ and country $B$ are, respectively:

\footnotetext{
${ }^{10}$ Of course, one could also assume that the richer country has the smaller population size, while the poorer country has the larger size. In this case, as clarified by Cabrales and Motta (2001), the main findings depend on whether the former force, namely the population size driver, prevails over the latter, namely the income driver.

Although the scope of their analysis is different from ours, since they investigate the effects of trade liberalization on product choice in a two-country model, Cabrales and Motta (2001) discuss the role of countries' asymmetry in terms of population size and average income in open economies.

${ }^{11}$ We can solve the model assuming exactly the opposite: brown good produced in the or richer country and green good produced in the poorer country. These calculations can be made available upon request.

${ }^{12}$ For simplicity, we postulate a linear positive relationship between the amount of the final good produced and the quantity of emissions as in Sanin and Zanaj (2011). A more complex correlation between production and emissions renders rather complex any comparison of total emissions across scenarios.
} 


$$
\begin{aligned}
E_{G}^{A} & =\alpha \frac{\Theta_{G}}{2} \text { and } E_{B}^{A}=\frac{\Theta_{B}}{2} \text { or } \\
E^{A} & =E_{G}^{A}+E_{B}^{A}=\frac{\alpha \Theta_{G}+\Theta_{B}}{2} .
\end{aligned}
$$

In the case of open economies the market structure is a duopoly with firms competing in an international economy. The corresponding demand function of each firm can be written as follows

$$
\begin{aligned}
& x_{G}\left(p_{G}, p_{B}\right)=\tau\left(\Theta_{B}-\frac{p_{G}-p_{B}}{q_{G}-q_{B}}\right)+\left(\Theta_{G}-\frac{p_{G}-p_{B}}{q_{G}-q_{B}}\right) \\
& x_{B}\left(p_{G}, p_{B}\right)=\frac{p_{G}-p_{B}}{q_{G}-q_{B}}-\frac{p_{B}}{q_{B}}+\tau\left(\frac{p_{G}-p_{B}}{q_{G}-q_{B}}-\frac{p_{B}}{q_{B}}\right)
\end{aligned}
$$

Maximizing profit $\pi_{i}=p_{i} x_{i}\left(p_{i}, p_{j}\right), i, j=B, G, i \neq j$, of firm $i$ yields the candidate equilibrium prices

$$
\begin{aligned}
& p_{G}^{*}=\left(q_{G}-q_{B}\right) \frac{\left(\Theta_{G}+\Theta_{B} \tau\right) 2 q_{G}}{\left(4 q_{G}-q_{B}\right)(\tau+1)} \\
& p_{B}^{*}=\left(q_{G}-q_{B}\right) \frac{\left(\Theta_{G}+\Theta_{B} \tau\right) q_{B}}{\left(4 q_{G}-q_{B}\right)(\tau+1)} .
\end{aligned}
$$

The corresponding demands at equilibrium write as

$$
x_{G}^{*}=\frac{2\left(\Theta_{G}+\Theta_{B} \tau\right) q_{G}}{4 q_{G}-q_{B}} \text { and } x_{B}^{*}=\frac{\left(\Theta_{G}+\Theta_{B} \tau\right) q_{G}}{4 q_{G}-q_{B}} .
$$

In this setting, the typical effects of trade on the equilibrium configuration emerge so that the equilibrium prices of the variants decrease and the corresponding demands raise as trade gets more and more liberalized.

Thus, at equilibrium, pollution damage writes as:

$$
\begin{aligned}
E_{G}^{*} & =\alpha \frac{2\left(\Theta_{G}+\Theta_{B} \tau\right) q_{G}}{4 q_{G}-q_{B}}, E_{B}^{*}=\frac{\left(\Theta_{G}+\Theta_{B} \tau\right) q_{G}}{4 q_{G}-q_{B}} \text { or } \\
E^{*} & =\frac{q_{G}\left(\Theta_{G}+\tau \Theta_{B}\right)(2 \alpha+1)}{\left(4 q_{G}-q_{B}\right)}
\end{aligned}
$$

It is worth noticing that

$$
\begin{aligned}
E_{G}^{A}-E_{G}^{*} & =-\frac{1}{2} \alpha \frac{\Theta_{G} q_{B}+4 \tau \Theta_{B} q_{G}}{4 q_{G}-q_{B}}<0 \\
E_{B}^{A}-E_{B}^{*} & =\frac{1}{2} \frac{4 \Theta_{B} q_{G}-\Theta_{B} q_{B}-2 \Theta_{G} q_{G}-2 \tau \Theta_{B} q_{G}}{4 q_{G}-q_{B}}<0 \text { iff } q_{G}<\breve{q}_{G},
\end{aligned}
$$

where $\breve{q}_{G} \equiv \frac{1}{2} \Theta_{B} \frac{q_{B}}{(2-\tau) \Theta_{B}-\Theta_{G}}$. So, emissions coming from the clean firm are higher under trade than in the case of closed economy, whatever the income asymmetry between countries. Rather, emissions from the brown firm are higher under trade if and only if $q_{G}$ is sufficiently low, namely $q_{G}<\breve{q}_{G}$. The rationale for this finding is that the green firm always takes advantage in terms of 
quantity from openness of markets: the benefit of offering a high quality variant in a new market (market expansion effect) overcompensates the possible reduction determined by competing against a rival in an open duopoly rather than being a monopoly in a closed economy (competition effect). The dirty firm instead raises its optimal quantity if its environmental quality is sufficiently similar to the green rival (i.e. $q_{G}$ relatively low), since only in this circumstance the reduction induced by competition against a high-quality rival is overcompensated by the market expansion benefit.

\section{Relative preferences in both countries}

We assume in this section that consumers in both countries display relative preferences. Accordingly, they benefit from a social/psychological premium if they buy the higher quality variant, or suffer a penalty if they buy the dirty product. We characterize the equilibrium configuration and consider the effect of trade liberalization on it.

Formally, the indirect utility function in country $i$, with $i=G, B$ writes as follows:

$$
U_{i}(\theta)=\left\{\begin{array}{cc}
\theta q_{B}-p_{B}-\gamma_{i}\left(q_{G}-q_{B}\right) & \text { if she buys B } \\
\theta q_{G}-p_{G}+\gamma_{i}\left(q_{G}-q_{B}\right) & \text { if she buys G } \\
0 & \text { otherwise }
\end{array}\right.
$$

In the above formulation, we add to the traditional utility function a social component $\gamma_{i}\left(q_{G}-q_{B}\right)$ capturing the existence of relative preferences. This term defines the social benefit (or the social punishment) which is obtained (or suffered) by the consumer when purchasing the green (or the brown) variant of the good. Ceteris paribus, this social component increases with the gap between environmental qualities: the higher the environmental quality of the green variant with respect to the dirty product, the stronger the social rewards or the fiercer the social punishment for the consumers. The intensity of the relative preferences is given by the parameter $\gamma_{i}$. When relative preferences are present in both countries, it is assumed $\gamma_{G}>\gamma_{B}$ and thus in the richer country $G$, the social drivers attached to the environmental quality are more significant than those in the poorer country $B$. This is in line with the idea that green norms are interiorized after the basic needs have been satisfied. ${ }^{13}$ Thus, the indifferent consumer between buying the green variant and the brown one in country $G$ and country $B, \bar{\theta}_{G}$ and $\bar{\theta}_{B}$, respectively write as

$$
\begin{aligned}
& \bar{\theta}_{G}\left(p_{G}, p_{B}\right)=\frac{p_{G}-p_{B}-2 \gamma_{G}\left(q_{G}-q_{B}\right)}{q_{G}-q_{B}} \\
& \bar{\theta}_{B}\left(p_{G}, p_{B}\right)=\frac{p_{G}-p_{B}-2 \gamma_{B}\left(q_{G}-q_{B}\right)}{q_{G}-q_{B}},
\end{aligned}
$$

while the indifferent consumer between buying the low quality variant and not buying at all, namely $\tilde{\theta}_{G}, \tilde{\theta}_{B}$ in country $G$ and country $B$, write as

$$
\tilde{\theta}_{G}\left(p_{B}\right)=\frac{p_{B}+\gamma_{G}\left(q_{G}-q_{B}\right)}{q_{B}} \text { and } \tilde{\theta}_{B}\left(p_{B}\right)=\frac{p_{B}+\gamma_{B}\left(q_{G}-q_{B}\right)}{q_{B}} .
$$

\footnotetext{
${ }^{13}$ See on this Ben-Elhadj and Tarola (2015).
} 
Finally $\hat{\theta}_{G}\left(p_{G}\right)=\frac{p_{G}-\gamma_{G}\left(q_{G}-q_{B}\right)}{q_{G}}$ and $\hat{\theta}_{B}\left(p_{G}\right)=\frac{p_{G}-\gamma_{B}\left(q_{G}-q_{B}\right)}{q_{G}}$, with $\hat{\theta}_{B}\left(p_{G}\right)>0$, iff $p_{G}>\gamma_{B}\left(q_{G}-q_{B}\right)$, represent the indifferent consumer between buying the high quality green variant and not buying at all in country $G$ and country $B$, respectively. In this framework, the demand functions faced by firms $G$ and $B$ write, respectively, as:

$$
\begin{aligned}
& x_{G}\left(p_{G}, p_{B}\right)=\tau\left(\Theta_{B}-K\right)+\Theta_{G}-k \\
& x_{B}\left(p_{G}, p_{B}\right)=K-\frac{p_{B}+\gamma_{B}\left(q_{G}-q_{B}\right)}{q_{B}}+\tau\left(k-\frac{p_{B}+\gamma_{G}\left(q_{G}-q_{B}\right)}{q_{B}}\right)
\end{aligned}
$$

where $K=\frac{p_{G}-p_{B}-2 \gamma_{B}\left(q_{G}-q_{B}\right)}{\left(q_{G}-q_{B}\right)}$ and $k=\frac{p_{G}-p_{B}-2 \gamma_{G}\left(q_{G}-q_{B}\right)}{\left(q_{G}-q_{B}\right)}$. Given the profit function $\pi_{i}\left(p_{i}, p_{j}\right)=p_{i} x_{i}\left(p_{i}, p_{j}\right), i, j=B, G, i \neq j$, the pair of equilibrium prices is easily found

$$
\begin{aligned}
p_{G}^{* *} & =\frac{\left(q_{G}-q_{B}\right)\left(\left(\Theta_{G}+\tau \Theta_{B}+2\left(\gamma_{G}+\tau \gamma_{B}\right)\right) 2 q_{G}-\left(\gamma_{B}+\tau \gamma_{G}\right)\left(q_{G}+q_{B}\right)\right)}{\left(4 q_{G}-q_{B}\right)(\tau+1)} \\
p_{B}^{* *} & =\frac{\left(q_{G}-q_{B}\right)\left(\left(\Theta_{G}+\tau \Theta_{B}+2\left(\gamma_{G}+\tau \gamma_{B}\right)\right) q_{B}-2\left(q_{G}+q_{B}\right)\left(\tau \gamma_{G}+\gamma_{B}\right)\right)}{\left(4 q_{G}-q_{B}\right)(\tau+1)} .
\end{aligned}
$$

The corresponding demands at equilibrium are then

$$
\begin{gathered}
x_{G}^{* *}=\frac{2\left(\Theta_{G}+\tau \Theta_{B}+2\left(\gamma_{G}+\tau \gamma_{B}\right)\right) q_{G}-\left(\gamma_{B}+\tau \gamma_{G}\right)\left(q_{G}+q_{B}\right)}{4 q_{G}-q_{B}} \\
x_{B}^{* *}=q_{G} \frac{\left(\left(\Theta_{G}+\tau \Theta_{B}+2\left(\gamma_{G}+\tau \gamma_{B}\right)\right) q_{B}-2\left(q_{G}+q_{B}\right)\left(\tau \gamma_{G}+\gamma_{B}\right)\right)}{q_{B}\left(4 q_{G}-q_{B}\right)} .
\end{gathered}
$$

Notice that $p_{G}^{* *}>0$ and $x_{G}^{* *}>0$ always hold whereas $p_{B}^{* *}$ and $x_{B}^{* *}$ are strictly positive iff $\Theta_{B} \geq$ $\check{\Theta}_{B}=\frac{2\left(\gamma_{B}+\tau \gamma_{G}\right)\left(q_{B}+q_{G}\right)-q_{B}\left(\Theta_{G}+2\left(\gamma_{G}+\tau \gamma_{B}\right)\right)}{\tau q_{B}}$. Since the social penalty reduces the price of the brown good, for its price to be positive, the average income of the poorer country has to be sufficiently high. Finally, we find emissions at equilibrium

$$
\begin{gathered}
E_{G}^{* *}=\frac{2 \alpha\left(\Theta_{G}+\tau \Theta_{B}+2\left(\gamma_{G}+\tau \gamma_{B}\right)\right) q_{G}-\left(\gamma_{B}+\tau \gamma_{G}\right)\left(q_{G}+q_{B}\right)}{4 q_{G}-q_{B}} \\
E_{B}^{* *}=q_{G} \frac{\left(\left(\Theta_{G}+\tau \Theta_{B} 2\left(\gamma_{G}+\tau \gamma_{B}\right)\right) q_{B}-2\left(q_{G}+q_{B}\right)\left(\tau \gamma_{G}+\gamma_{B}\right)\right)}{q_{B}\left(4 q_{G}-q_{B}\right)} .
\end{gathered}
$$

Denoting by $\breve{\tau}=\frac{\gamma_{B} q_{B}+\gamma_{B} q_{G}-\gamma_{G} q_{B}}{\gamma_{B} q_{B}-\gamma_{G} q_{B}-\gamma_{G} q_{G}}$ the value of $\tau$ such that $E_{B}^{* *}(\breve{\tau})=E_{B}^{*}(\breve{\tau})$, we observe that

Proposition 1 Relative preferences raise the equilibrium price and quantity of the green variant w.r.t. the baseline, whatever the level of trade liberalization. By contrast, they reduce the equilibrium price and the corresponding quantity of the brown good w.r.t. the baseline, when the international trade is sufficiently liberalized $(\tau>\breve{\tau})$. In this case, global emissions can decrease.

Proof. The effects of relative preferences on prices and quantity immediately derive from direct comparison of the expressions. As far as the emissions is concerned, first notice that $\left(E_{G}^{* *}+E_{B}^{* *}\right)-$ $\left(E_{G}^{*}+E_{B}^{*}\right)=\frac{\left(-\gamma_{B}-\tau \gamma_{G}\right) 2 q_{G}^{2}+\left(2 \gamma_{G}-2 \gamma_{B}-\alpha \gamma_{B}+2 \tau \gamma_{B}+4 \alpha \gamma_{G}-2 \tau \gamma_{G}+4 \alpha \tau \gamma_{B}-\alpha \tau \gamma_{G}\right) q_{G} q_{B}-\left(\gamma_{B}+\tau \gamma_{G}\right) \alpha q_{B}^{2}}{q_{B}}<0$ iff $\tau>\bar{\tau}=\frac{-\left(2 \gamma_{B} q_{G}^{2}+\alpha \gamma_{B} q_{B}^{2}+2 \gamma_{B} q_{B} q_{G}-2 \gamma_{G} q_{B} q_{G}+\alpha \gamma_{B} q_{B} q_{G}-4 \alpha \gamma_{G} q_{B} q_{G}\right)}{2 \gamma_{G} q_{G}^{2}+\alpha \gamma_{G} q_{B}^{2}-2 \gamma_{B} q_{B} q_{G}+2 \gamma_{G} q_{B} q_{G}-4 \alpha \gamma_{B} q_{B} q_{G}+\alpha \gamma_{G} q_{B} q_{G}}$. Since $\bar{\tau} \lessgtr \breve{\tau}$, then $\left(E_{G}^{* *}+E_{B}^{* *}\right)-$ $\left(E_{G}^{*}+E_{B}^{*}\right)<0$ whenever $\tau>\max [\bar{\tau}, \breve{\tau}]$.

In the case when $\tau>\breve{\tau}$, our finding on the equilibrium price of the brown variant is in line with that emerging in Ben-Elhadj and Tarola (2015) where firms produce and sell in their home 
market and exports are not contemplated. Indeed, when trade liberalization is very significant, it is as if the two areas would collapse to a single market. In this circumstance, one can isolate two drivers of equilibrium prices: a price competition driver and a social driver. The former driver, which is typically observed in a vertically differentiated model, is such that the larger the quality gap between variants, the less fierce the price competition in the market and thus the higher the equilibrium prices. The latter is rather linked to the social component of consumption so that the social benefit of buying green raises the equilibrium price of the green variant to the extent that the social punishment reduces the equilibrium price of the competing and dirty product. Notice that

Remark $\quad \breve{\tau}<0 \Leftrightarrow q_{G}>\breve{q}_{G}$ with $\breve{q}_{G}=\left(\frac{\gamma_{G}}{\gamma_{B}}-1\right) q_{G}$.

Clearly, the condition $\tau>\breve{\tau}$ is always met when $\breve{\tau}<0$, namely when the green variant has a very high environmental quality $\left(q_{G}>\breve{q}_{G}\right)$. Interestingly, the threshold value $\breve{q}_{G}$ increases in $\gamma_{G}$ and decreases in $\gamma_{B}$. Accordingly, the lower (resp. the higher) the environmental concern in the richer (resp. poorer) country, the larger the set of $q_{G}-$ values such that $\breve{\tau}<0$. In this case, the price competition driver moves upward the price of the brown good, while the social driver emphasizes the social frustration of buying the brown good thereby reducing its corresponding price. This latter force prevails over the former so that the equilibrium price of the brown product under relative preferences is lower than in the baseline scenario.

It is worth noticing that, when the international trade is sufficiently liberalized, the existence of relative preferences reduces global emissions. Hence, a social content to green and brown products and a significant trade liberalization benefit environmentally virtuous firms and curb global emissions. This no longer holds when trade liberalization is not pronounced. With high trade costs, a widespread green awareness does not contribute to reduce emissions.

To summarize, while relative preferences can reduce emissions of the brown country, they always raise the equilibrium quantity produced in the green country and thus, ceteris paribus, the corresponding emissions. Hence, the clean country becomes dirtier, whatever the level of trade liberalization, while the brown counterpart becomes cleaner if and only if international trade is sufficiently liberalized. Still, when these preferences emerge in a setting where trade is intense, pollution of the brown country decreases to such an extent to counterbalance the raise in emissions of the clean one.

We investigate now the role of trade liberalization on the equilibrium configuration.

Let us denote $\bar{\gamma}_{G}=\frac{\left(2 \Theta_{B} q_{G}+4 \gamma_{B} q_{G}\right)}{q_{B}+q_{G}}$ and $\gamma_{G}^{\prime}=\frac{\left(\Theta_{B} q_{B}+2 \gamma_{B} q_{B}\right)}{2 q_{B}+2 q_{G}}$, with $\gamma_{G}^{\prime}<\bar{\gamma}_{G}$, and $\breve{\alpha}=\frac{q_{G}}{q_{B}} \frac{-2 \gamma_{G} q_{G}+\Theta_{B} q_{B}+2 \gamma_{B} q_{B}-2 \gamma_{G} q_{B}}{\gamma_{G} q_{B}-2 \Theta_{B} q_{G}-4 \gamma_{B} q_{G}+\gamma_{G} q_{G}}$.

Then,

\section{Proposition 2 Trade liberalization}

(i) decreases the quantity sold by each firm iff the social component in country $G$ is strong $\left(\gamma_{G}>\bar{\gamma}_{G}\right)$. In this case, global emissions unambiguously decrease.

(ii) increases the quantity sold by firm $G$ while it reduces the quantity of firm B iff the social component in country $G$ is moderate $\left(\gamma_{G}^{\prime}<\gamma_{G}<\bar{\gamma}_{G}\right)$. In this case, global emissions decrease 
whenever the high environmentally friendly variant is sufficiently green $(\alpha<\min [\breve{\alpha}, 1])$.

(iii) Finally, it increases the quantity sold by each firm with a raise in global emissions iff the social driver of consumption in country $G$ is weak $\left(\gamma_{G}<\gamma_{G}^{\prime}\right)$.

Proof. As far as the effect of trade liberalization on equilibrium quantity, from standard computations we find that $\frac{\partial x_{G}^{* *}}{\partial \tau}=\frac{2 \Theta_{B} q_{G}+4 \gamma_{B} q_{G}-\gamma_{G} q_{G}-\gamma_{G} q_{B}}{4 q_{G}-q_{B}} \gtreqless 0 \Leftrightarrow \gamma_{G} \lessgtr \bar{\gamma}_{G} \equiv \frac{\left(2 \Theta_{B} q_{G}+4 \gamma_{B} q_{G}\right)}{q_{B}+q_{G}} ; \frac{\partial x_{B}^{* *}}{\partial \tau}=$ $q_{G} \frac{\Theta_{B} q_{B}+2 \gamma_{B} q_{B}-2 \gamma_{G} q_{G}-2 \gamma_{G} q_{B}}{q_{B}\left(4 q_{G}-q_{B}\right)} \gtreqless 0 \Leftrightarrow \gamma_{G} \lessgtr \gamma_{G}^{\prime} \equiv \frac{\left(\Theta_{B} q_{B}+2 \gamma_{B} q_{B}\right)}{2 q_{B}+2 q_{G}} ; \bar{\gamma}_{G}-\gamma_{G}^{\prime}=\frac{1}{2}\left(\Theta_{B}+2 \gamma_{B}\right) \frac{4 q_{G}-q_{B}}{q_{B}+q_{G}}>0$. As far as emissions, in the extreme case of high and low social environmental awareness, the result is straightforward. In the intermediate case, we observe $\frac{\partial\left(E_{G}^{* *}+E_{G}^{* *}\right)}{\partial \tau}=a \frac{2 \Theta_{B} q_{G}+4 \gamma_{B} q_{G}-\gamma_{G} q_{G}-\gamma_{G} q_{B}}{\left(4 q_{G}-q_{B}\right)}+$ $q_{G} \frac{\Theta_{B} q_{B}+2 \gamma_{B} q_{B}-2 \gamma_{G} q_{G}-2 \gamma_{G} q_{B}}{q_{B}\left(4 q_{G}-q_{B}\right)}=\frac{\left(2 \Theta_{B} q_{B} q_{G}-\gamma_{G} q_{B}^{2}+4 \gamma_{B} q_{B} q_{G}-\gamma_{G} q_{B} q_{G}\right) a+\left(\Theta_{B} q_{B} q_{G}-2 \gamma_{G} q_{G}^{2}+2 \gamma_{B} q_{B} q_{G}-2 \gamma_{G} q_{B} q_{G}\right)}{q_{B}\left(4 q_{G}-q_{B}\right)}$ with the numerator being negative iff $\alpha<\bar{a}=\frac{\left(-2 \gamma_{G} q_{G}^{2}+\Theta_{B} q_{B} q_{G}+2 \gamma_{B} q_{B} q_{G}-2 \gamma_{G} q_{B} q_{G}\right)}{\gamma_{G} q_{B}^{2}-2 \Theta_{B} q_{B} q_{G}-4 \gamma_{B} q_{B} q_{G}+\gamma_{G} q_{B} q_{G}}$. Moreover $\breve{\alpha}>1$ iff $\Theta_{B}<\bar{\Theta}_{B}=\frac{\left(\gamma_{G} q_{B}^{2}+2 \gamma_{G} q_{G}^{2}-6 \gamma_{B} q_{B} q_{G}+3 \gamma_{G} q_{B} q_{G}\right)}{3 q_{B} q_{G}}$.

It is worth noticing that whenever relative preferences are extremely significant, both the clean and the dirty countries become cleaner with trade. Nowadays, with people being increasingly aware of environmental issues and the effort made for liberalizing trade, we can reasonable guess that this eco-friendly path will be likely to emerge.

Proposition 3 Trade liberalization reduces both equilibrium prices.

Proof. Straightforward for direct comparison.

This finding sounds surprising: trade liberalization can reduce the equilibrium quantities while decreasing their price, with a positive effect on environment. In particular, these effects emerge when the intensity of social preferences in country $G$ is relevant. Traditionally liberalizing the trade determines a reduction of the equilibrium prices with a corresponding increase of the traded quantity. The rationale for our result can be captured as follows. Due to trade liberalization, the equilibrium price of both variants decreases. Since the social component in country $G$ driven by $\gamma_{G}\left(q_{G}-q_{B}\right)$ is very significant, the price of the green variant decreases proportionally less than the price of the brown good. This reduction in prices has a cross-effect: the quantity of the variant $i$ reduces as a consequence of the price reduction of the competing variant $j$. Still, the reduction of $x_{B}^{* *}$ is less significant than that of $x_{G}^{* *}$ : the high intensity of the social component $\gamma_{G}$ in country $G$ magnifies the benefit (resp. punishment) of buying the green (resp. dirty) good thereby restraining the reduction of its price $p_{G}^{* *}$ while increasing that of the corresponding demand. In this circumstance, global emissions clearly decrease. This environmental benefit can still hold when the market share of the green firm raise. In particular, this is the case if the green variant has extremely low emissions per unit of production $(\alpha<\min [\breve{\alpha}, 1])$.

The traditional effects determined by trade liberalization, with reduction in prices and increases in demand, are observed when the social component gets weaker and weaker.

Last, $\bar{\gamma}_{G}$ increases with $q_{G}$ while $\gamma_{G}^{\prime}$ decreases with $q_{G}$. Accordingly, the higher the value of $q_{G}$, the larger the set of parameters such that $\gamma_{G}^{\prime}<\gamma_{B}<\bar{\gamma}_{G}$ holds. So, a product innovation increasing 
the environmental quality of the green good makes the green firm better off, while making worse off the brown rival, ceteris paribus.

\section{Relative preferences in one country}

We assume now that relative preferences are present in only one of two countries. First, we consider the scenario where consumers in the poorer country have relative preferences, those in the richer country having the traditional utility function. More specifically, in this case we assume $\gamma_{G}=0$. Then, we move to the case in which consumers' preferences and firms production are aligned: the green (resp. brown) firm is located where consumers displays more (resp. less) sensitivity for the environment. Hence, in this case, we assume $\gamma_{B}=0$. In both these scenarios the role of trade cost is crucial.

\subsection{Relative preferences in country $B$}

In this scenario, we assume that relative preferences emerge in country $B$ where the more pollutant production activity is located. The pair of equilibrium prices $\check{p}_{i}, i=G, B$ writes as

$$
\begin{aligned}
& \check{p}_{G}=\left(q_{G}-q_{B}\right) \frac{\left(\Theta_{G}+\Theta_{B} \tau+2 \tau \gamma_{B}\right) 2 q_{G}-\gamma_{B}\left(q_{G}+q_{B}\right)}{\left(4 q_{G}-q_{B}\right)(\tau+1)} \\
& \check{p}_{B}=\left(q_{G}-q_{B}\right) \frac{\left(\Theta_{G}+\Theta_{B} \tau+2 \tau \gamma_{B}\right) q_{B}-2 \gamma_{B}\left(q_{G}+q_{B}\right)}{\left(4 q_{G}-q_{B}\right)(\tau+1)}
\end{aligned}
$$

with the corresponding demand at equilibrium being:

$$
\begin{aligned}
& \check{x}_{G}=\frac{\left(\Theta_{G}+\Theta_{B} \tau+2 \tau \gamma_{B}\right) 2 q_{G}-\gamma_{B}\left(q_{G}+q_{B}\right)}{4 q_{G}-q_{B}} \\
& \check{x}_{B}=q_{G} \frac{\left(\Theta_{G}+\Theta_{B} \tau+2 \tau \gamma_{B}\right) q_{B}-2 \gamma_{B}\left(q_{G}+q_{B}\right)}{q_{B}\left(4 q_{G}-q_{B}\right)} .
\end{aligned}
$$

The candidate equilibrium price $\check{p}_{B}$ is positive iff

$$
\Theta_{G}>\bar{\Theta} \text { with } \bar{\Theta}=\frac{2 \gamma_{B}\left(q_{G}+q_{B}\right)-2 \tau \gamma_{B} q_{B}}{q_{B}}-\Theta_{B} \tau .
$$

Since $\bar{\Theta}>\breve{\Theta}$, then $\check{p}_{B}>0 \Leftrightarrow \check{p}_{G}>0$. The price of the green variant $\check{p}_{G}$ is positive if and only if the richer country $G$ has a sufficiently high average income, namely $\Theta_{G}>\breve{\Theta}$ where $\breve{\Theta}$ $=\frac{\gamma_{B}\left(q_{B}+q_{G}\right)-4 \tau \gamma_{B} q_{G}}{2 q_{G}}-\Theta_{B} \tau$ with $\breve{\Theta} \geq 0$ for $\Theta_{B} \leq \frac{1}{2 \tau q_{G}}\left(\gamma_{B}\left(q_{B}+q_{G}\right)-4 \tau \gamma_{B} q_{G}\right)$. When relative preferences are present in both countries, the positivity of the price of the green variant was met, regardless of the average income in country $G$. This is due to the fact that now the social reward from buying the green variant is weaker than in that setting. As immediate consequence, the green price is lower under relative preferences in country $B$ than under relative preferences in both countries.

At this equilibrium configuration, pollution damage writes as

$$
\begin{aligned}
\check{E}_{G} & =\alpha \frac{\left(\Theta_{G}+\Theta_{B} \tau+2 \tau \gamma_{B}\right) 2 q_{G}-\gamma_{B}\left(q_{G}+q_{B}\right)}{4 q_{G}-q_{B}} \\
\check{E}_{B} & =q_{G} \frac{\left(\Theta_{G}+\Theta_{B} \tau+2 \tau \gamma_{B}\right) q_{B}-2 \gamma_{B}\left(q_{G}+q_{B}\right)}{q_{B}\left(4 q_{G}-q_{B}\right)} .
\end{aligned}
$$


Then, denoting by $\dot{\tau}=\frac{q_{B}+q_{G}}{4 q_{G}}$ we find that

Proposition 4 Compared with the baseline scenario, relative preferences only in the brown market (i) reduce the equilibrium price and the corresponding demand of the brown good; while (ii) raise both the equilibrium price and demand of the green variant iff trade is sufficiently liberalized $(\tau>\dot{\tau})$. Even when raising the market share of the green firm, they reduce global emissions.

Proof. From direct comparison of the expressions.

Accordingly, when the social component of consumption holds only in the poorer country, the brown firm is penalized by the existence of relative preferences, regardless of trade costs: the social penalty suffered by consumers when buying the dirty product moves downward its price. Along the same rationale, the green firm benefits from these preferences only under a sufficiently high liberalization: when trade costs are not relevant, the environmental awareness in country $B$ turns out to be significant, thereby moving upward the willingness to pay for the green good and thus its equilibrium price $\check{p}_{G}$.

Nonetheless, it gets higher than in the baseline, namely $p_{G}^{* *}>\check{p}_{G}>p_{G}^{*}$. Interestingly, these preferences are environment improving. Whatever the trade liberalization, global emissions decrease.

We investigate now the role of trade liberalization on the equilibrium configuration, under the assumption of relative preferences in country $B$. Typically, as a natural consequence of trade liberalization, equilibrium prices of the traded goods tend to reduce while demand of products to increase. This phenomenon determines a positive effect on consumers' surplus and possibly on firms' profits if the increase in quantity can countervail the reduction in prices.

Let us define $\check{\gamma}=\frac{2 \Theta_{G} q_{G}-2 \Theta_{B} q_{G}}{q_{B}+5 q_{G}}$ and $\hat{\gamma}=\frac{\Theta_{G} q_{B}-\Theta_{B} q_{B}}{4 q_{B}+2 q_{G}}$. We claim the following proposition:

\section{Proposition 5 Trade liberalization}

(i) increases (resp. decreases) both prices whenever the intensity of relative preferences is high (resp. low), namely iff $\gamma_{B}>\check{\gamma}\left(\right.$ resp. $\gamma_{B}<\hat{\gamma}$ ). For any $\check{\gamma}>\gamma_{B}>\hat{\gamma}$, it increases the price of the brown variant and decreases the one of the green firm.

(ii) always increases the quantity produced by both firms and thus it is environment detrimental.

Proof. $\frac{\partial \breve{p}_{G}}{\partial \tau}=\left(q_{G}-q_{B}\right) \frac{\gamma_{B} q_{B}+5 \gamma_{B} q_{G}+2 \Theta_{B} q_{G}-2 \Theta_{G} q_{G}}{\left(4 q_{G}-q_{B}\right)(\tau+1)^{2}} \gtreqless 0 \Leftrightarrow \gamma_{B} \gtreqless \check{\gamma}=\frac{2 \Theta_{G} q_{G}-2 \Theta_{B} q_{G}}{q_{B}+5 q_{G}}$

$\frac{\partial \breve{p}_{B}}{\partial \tau}=\left(q_{G}-q_{B}\right) \frac{4 \gamma_{B} q_{B}+2 \gamma_{B} q_{G}+\Theta_{B} q_{B}-\Theta_{G} q_{B}}{\left(4 q_{G}-q_{B}\right)(\tau+1)^{2}} \gtreqless 0 \Leftrightarrow \gamma_{B} \gtreqless \hat{\gamma}=\frac{\Theta_{G} q_{B}-\Theta_{B} q_{B}}{4 q_{B}+2 q_{G}}$.

with $\check{\gamma}-\hat{\gamma}=\frac{\left(4 q_{G}-q_{B}\right)\left(q_{B}+q_{G}\right)\left(\Theta_{G}-\Theta_{B}\right)}{\left(2 q_{B}+q_{G}\right)\left(q_{B}+5 q_{G}\right)}>0$. The effect on global emissions is straightforward.

The rationale underlying the above Proposition can be expressed as follows. When the social component of consumption is very significant, trade liberalization benefits both firms: the green producer takes advantage from the social component in country $B$ which moves upward their willingness to pay for the environmentally friendly good and, thus, the equilibrium price of the green 
variant. Since prices are strategic complements, the higher the equilibrium price $\breve{p}_{G}$, the higher the equilibrium price of the competing variant. When the social component is low, the traditional findings emerge, with trade liberalization reducing prices and increasing the corresponding traded quantities. Finally, for intermediate values of the social component, on one hand the social punishment penalizing the dirty product is weak so that the brown firm can get benefit from exporting to the richer country and selling to consumers who disregard the social content of the goods. On the other hand, the price of the green variant is moved downward by the low willingness to pay of consumers in country $B$, for which the social rewards of buying socially worthy goods play a minor role.

Rather surprisingly, it emerges that when the social component affects consumers' preferences only in poorer countries where dirty goods are produced, the process of trade liberalization can favor brown producers, while penalizing green firms.

This effect is never found in the scenario with relative preferences in both countries. In that case, both equilibrium prices decrease with trade liberalization; further, when the social component is extremely significant, the equilibrium quantities decrease as well, with a negative effect on profits of both producer. Still, when this component is not so relevant, it may happen that the equilibrium quantity of the green good increase with trade liberalization, while that of the brown product decreases. When this happens, it may hold that the green producer takes advantage from the liberalization of the trade, while the brown producer is penalized from it.

Finally, we notice that trade liberalization is always environmental detrimental since it raise both equilibrium quantities.

\subsection{Relative preferences in country G}

In this setting with relative preferences arising only in country $G$, we observe the same qualitative findings emerging when relative preferences arise in both countries. For clarity of exposition, we relegate to the Appendix A the formal details of this scenario. We find that relative preferences reduce the price and the quantity of the brown variant at equilibrium w.r.t. the baseline when the international market is free enough, while raise the equilibrium price and quantity of the green product, irrespective of trade cost.

Further, in line with the general analysis, we observe that whenever the intensity of relative preferences is relatively low (resp. high), trade liberalization raises (resp. decreases) the equilibrium demand of both brown and green goods. For intermediate values of this intensity, the demand of the green good increases while that of the brown good decreases. Both equilibrium prices decrease with trade liberalization. Relative preferences reduce global emissions w.r.t. the baseline for a sufficiently high value of $\tau$ and trade liberalization is unambiguously environmental enhancing only when relative preferences are weak. Otherwise, for global emissions to decrease with trade liberalization, the emissions generated from the green product per unit of production have to be sufficiently low. ${ }^{14}$ Nevertheless, it is interesting to notice that:

\footnotetext{
${ }^{14}$ See Appendix C for formal details.
} 
Proposition 6 Trade liberalization favors the green producer more when consumers in both countries display relative preferences than in the case when these preferences arise only in country $G$.

Proof. See Appendix B.

Clearly, the larger the number of countries, in which consumers show relative preferences, the stronger the incentive for firms to produce green goods in the light of the increasing liberalization process.

\section{A natural extension: quality competition}

In our analysis, we have assumed that firms only compete in price, the quality of goods being given. While this statement represents a natural entry point of the analysis, it could be interesting to extend the model to the case where firms define their optimal quality in order to obtain some intuitions about the role of environmental relative preferences and trade liberalization when quality is endogenously selected by the firms. To this aim, we simplify the analysis by fixing $\Theta_{G}=\Theta_{B}$. Under this assumption, countries no longer differ in average income and they present the same population size.

In this simplified scenario, first we can prove that the profit function of the green good is monotonically increasing in $q_{G}$ (see Appendix D). Although this finding comes with no surprise, absent quality specific production costs, it enables us to conclude that the green firm chooses the highest possible quality. Whereas for the brown firm, we identify a threshold of $\gamma_{G}$ that determine two intervals.

In the first, for relatively high levels of intensity of relative preferences, the brown firm chooses a low quality in order to soften price competition. In the second, for relatively low intensity of relative preferences, the brown firm chooses to be closer to the green firm's quality, because of the strong loss in market share in presence of relative preferences.

We summarize the above findings in the following proposition.

Proposition 7 In the case of endogenous quality, the green firm sets it optimal quality at the highest level, its profit being monotonically increasing in $q_{G}$. The brown competitor chooses the optimal quality gap, depending on the intensity of relative preferences. In particular, the optimal quality $q_{B}$ is set close to $q_{G}$ for a low intensity of relative preferences.

What is the effect of trade liberalization when qualities are endogenous? We observe that while the threshold value $\bar{\gamma}_{G}$ increases in $q_{G}$ and decreases in $q_{B}$, the opposite holds for $\gamma_{G}^{\prime}$, which is higher, the lower is $q_{G}$ and the higher is $q_{B}$. Accordingly, when the brown quality is set close to the green variant, the condition $\gamma>\bar{\gamma}_{G}$ is more easily satisfied. Hence, in presence of relative preferences, using the result of the Proposition 2 in point (i), endogenous quality choices enlarges the set of parameters such that emissions decrease with trade liberalization. Rather, in the case where the brown firms chooses to be far from the firm in terms of quality, the interval such that 
$\gamma_{G}^{\prime}<\gamma_{G}<\bar{\gamma}_{G}$ enlarges and global emissions can decrease with trade liberalization, as stated in point (ii) of the same proposition.

\section{Conclusions}

Status goods are as old as humanity. In the ancient Rome, when plebeians became so rich to decorate their homes, then the Roman elites installed mosaics in their villas. At the end of the 19th century, Thorstein Veblen noted in "The Theory of the Leisure Class" - the book in which he coined the phrase "conspicuous consumption" - spending lavishly on expensive but essentially wasteful goods and services is "evidence of wealth" and the "failure to consume in due quantity and quality becomes a mark of inferiority and demerit."

In the present paper, we have argued that in the 21st century, the list of status good that serves to give status among peers has changed considerably including environmentally friendly goods. These preferences are named environmental relative preferences and their presence may induce unexpected effects of trade liberalization on the environment.

The main result of our model is that trade liberalization can reduce the equilibrium quantities while decreasing their price, with a positive effect on the environment (Proposition 2 and 3). This is a key result in view of the highly intensified international trade relations worldwide during the last 3 decades. Further, this is a result that can be empirically tested. More specifically, a first empirically testable result of our model is that (i) global emissions decrease with trade liberalization if relative preferences are present and thus interiorized by both rich and poor countries. In addition, (ii) trade liberalization may lead to an increase in prices and in the level of production of brown goods, if developed and emerging countries show significant differences in relative preferences. It follows that we can empirically investigate whether environmental relative preferences are present in the developing and developed country; as well as, the threshold value of environmental preferences intensity so as further increasing international trade relations is not detrimental for the environment.

We remain optimistic that relying on the rich databases available nowadays, namely in the presence of a common set of observables as average income of countries; trade costs measures, population size; indicators of environmental quality as environmental Performance Index (EPI) and/or CO2 emissions, we can answer satisfactorily the above questions.

\section{Appendix}

\section{Appendix A: Relative preferences in country G}

In this section, we provide the details for the scenario in which relative preferences appear in country $\mathrm{G}$. We find that the equilibrium prices are given by

$$
\begin{aligned}
& p_{G}^{* * *}=\left(q_{G}-q_{B}\right) \frac{\left(\Theta_{G}+\Theta_{B} \tau+2 \gamma\right) 2 q_{G}-\gamma \tau\left(q_{G}+q_{B}\right)}{\left(4 q_{G}-q_{B}\right)(\tau+1)} \\
& p_{B}^{* * *}=\left(q_{G}-q_{B}\right) \frac{\left(\Theta_{G}+\Theta_{B} \tau+2 \gamma\right) q_{B}-2 \gamma \tau\left(q_{G}+q_{B}\right)}{\left(4 q_{G}-q_{B}\right)(\tau+1)}
\end{aligned}
$$


Notice that $p_{G}^{* * *}>0$ always holds while the positivity of the equilibrium price $p_{B}^{* *}$ is met iff $\Theta_{B} \geq \dot{\Theta}_{B}$ where $\dot{\Theta}_{B}=\frac{2 \tau \gamma\left(q_{B}+q_{G}\right)-q_{B}\left(2 \gamma+\Theta_{G}\right)}{\tau q_{B}}$.

The corresponding equilibrium market shares are then:

$$
\begin{aligned}
& x_{G}^{* * *}=\frac{\left(\Theta_{G}+2 \gamma+\Theta_{B} \tau\right) 2 q_{G}-\gamma \tau\left(q_{G}+q_{B}\right)}{4 q_{G}-q_{B}} \\
& x_{B}^{* * *}=q_{G} \frac{\left(\Theta_{G}+2 \gamma+\Theta_{B} \tau\right) q_{B}-2 \gamma \tau\left(q_{G}+q_{B}\right)}{q_{B}\left(4 q_{G}-q_{B}\right)} .
\end{aligned}
$$

For the positivity of the market share $x_{B}^{* * *}$, the same argument used about $p_{B}^{* * *}$ applies so that $x_{B}^{* * *}>0$ iff $\Theta_{B} \geq \dot{\Theta}_{B}$.

\section{Appendix B: Proof of Proposition 6}

From standard computations, $\frac{\partial x_{G}^{* *}}{\partial \tau}=\frac{\Theta_{B} q_{B}-2 \gamma q_{B}-2 \gamma q_{G}}{q_{B}\left(4 q_{G}-q_{B}\right)} \gtreqless 0 \Leftrightarrow \gamma \lesseqgtr \dot{\gamma}$ and $\frac{\partial x_{B}^{* *}}{\partial \tau}=\frac{\gamma q_{B}+\gamma q_{G}-2 \Theta_{B} q_{G}}{q_{B}-4 q_{G}} \gtreqless$ $0 \Leftrightarrow \gamma \lesseqgtr \ddot{\gamma}$. Notice that $\ddot{\gamma}<\dot{\gamma}<\gamma_{G}^{\prime}$ always holds. Accordingly, when $\ddot{\gamma}<\dot{\gamma}<\gamma<\gamma_{G}^{\prime}$, then the equilibrium demand of the green goods increases with trade liberalization in the general setting with relative preferences in both countries. Still, it reduces in the particular case where relative preferences arise only in country $G$.

\section{Appendix C: Analysis of Emissions}

Let $E_{G}^{* * *}=\alpha \frac{\left(\Theta_{G}+2 \gamma+\Theta_{B} \tau\right) 2 q_{G}-\gamma \tau\left(q_{G}+q_{B}\right)}{4 q_{G}-q_{B}}$ and $E_{B}^{* * *}=q_{G} \frac{\left(\Theta_{G}+2 \gamma+\Theta_{B} \tau\right) q_{B}-2 \gamma \tau\left(q_{G}+q_{B}\right)}{q_{B}\left(4 q_{G}-q_{B}\right)}$

be the global emissions coming from firms $G$ and $B$, respectively in the case when relative preferences only emerge in county $G$, so that

$$
\begin{aligned}
E_{G}^{*} & =\alpha \frac{2\left(\Theta_{G}+\Theta_{B} \tau\right) q_{G}}{4 q_{G}-q_{B}}, E_{B}^{*}=\frac{\left(\Theta_{G}+\Theta_{B} \tau\right) q_{G}}{4 q_{G}-q_{B}} \text { or } \\
E^{*} & =\frac{q_{G}\left(\Theta_{G}+\tau \Theta_{B}\right)(2 \alpha+1)}{\left(4 q_{G}-q_{B}\right)}
\end{aligned}
$$

Then,

$$
E^{* * *}-E_{G}^{*}=\gamma \frac{-2 q_{B} q_{G}+2 \tau q_{G}^{2}+\alpha \tau q_{B}^{2}-4 \alpha q_{B} q_{G}+2 \tau q_{B} q_{G}+\alpha \tau q_{B} q_{G}}{q_{B}\left(q_{B}-4 q_{G}\right)} .
$$

Since the denominator is negative, the sign of the above difference depends on the numerator. From standard algebra, we immediately obtain that $-2 q_{B} q_{G}+2 \tau q_{G}^{2}+\alpha \tau q_{B}^{2}-4 \alpha q_{B} q_{G}+2 \tau q_{B} q_{G}+\alpha \tau q_{B} q_{G}>$ 0 iff $\tau>\ddot{\tau}=2 q_{B} q_{G} \frac{2 \alpha+1}{\left(q_{B}+q_{G}\right)\left(2 q_{G}+\alpha q_{B}\right)}$. Accordingly, we conclude that $E^{* * *}-E_{G}^{*}<0$ iff $\tau>\ddot{\tau}$.

As far as the effect of trade on emissions, we observe that

$$
\begin{aligned}
& \frac{\partial x_{G}}{\partial \tau}=\frac{\gamma q_{B}+\gamma q_{G}-2 \Theta_{B} q_{G}}{q_{B}-4 q_{G}}<0 \text { since } \Theta_{B}>\gamma \\
& \frac{\partial x_{B}}{\partial \tau}=q_{G} \frac{2 \gamma q_{B}+2 \gamma q_{G}-\Theta_{B} q_{B}}{q_{B}\left(q_{B}-4 q_{G}\right)} \gtreqless 0 \text { iff } \gamma \lesseqgtr \gamma_{B}=\frac{\Theta_{B} q_{B}}{2 q_{G}+2 q_{B}}
\end{aligned}
$$




\section{Appendix D: Endogenous quality choice}

As in the standard vertical differentiation model, the choice of prices and qualities can be modelled as a two-stage game in which in the first stage firms select the quality of the variant they produce and, in the second stage, firms select prices.

We reconsider the framework of Section 5 assuming for simplicity $\Theta_{G}=\Theta_{B}=\Theta$. Following the same procedure, we obtain the candidate equilibrium prices as

$$
\begin{aligned}
& p_{G}^{*}=\frac{q_{G}-q_{B}}{\left(4 q_{G}-q_{B}\right)(\tau+1)}\left(2 q_{G}\left(\Theta+\Theta \tau+2\left(\gamma_{G}+\tau \gamma_{B}\right)\right)-\left(q_{G}+q_{B}\right)\left(\tau \gamma_{G}+\gamma_{B}\right)\right) \\
& p_{B}^{*}=\frac{q_{G}-q_{B}}{\left(4 q_{G}-q_{B}\right)(\tau+1)}\left(q_{B}\left(\Theta+\Theta \tau+2\left(\gamma_{G}+\tau \gamma_{B}\right)\right)-\left(q_{G}+q_{B}\right)\left(2 \tau \gamma_{G}+2 \gamma_{B}\right)\right)
\end{aligned}
$$

Positivity of both prices is guarantied when $\Theta>\Theta_{\max } \equiv-\frac{1}{q_{B}} \frac{q_{B}\left(2 \gamma_{G}+2 \tau \gamma_{B}\right)-\left(2 \gamma_{B}+2 \tau \gamma_{G}\right)\left(q_{B}+q_{G}\right)}{\tau+1}$, namely when the size of the market is sufficiently large to let both variants of the goods to be produced in the market with $p_{G}^{*}-p_{B}^{*}>0$. Demands of firms $\mathrm{G}$ and $\mathrm{B}$ are then given by

$$
\begin{gathered}
x_{G}^{*}=\frac{q_{G}\left(2 \Theta+2 \Theta \tau+4 \gamma_{G}+4 \tau \gamma_{B}\right)-\left(q_{G}+q_{B}\right)\left(\tau \gamma_{G}+\gamma_{B}\right)}{4 q_{G}-q_{B}} \\
x_{B}^{*}=q_{G} \frac{q_{B}\left(\Theta+\Theta \tau+2 \gamma_{G}+2 \tau \gamma_{B}\right)-2\left(q_{G}+q_{B}\right)\left(\tau \gamma_{G}+\gamma_{B}\right)}{q_{B}\left(4 q_{G}-q_{B}\right)}
\end{gathered}
$$

Even in the case of the market share, we find that for the positivity of $x_{G}^{*}$ and $x_{B}^{*}$ is satisfied for a large overall market size $\Theta$. By plugging demands and prices in equilibrium into the profit functions, we find

$$
\begin{aligned}
& \pi_{G}^{*}\left(q_{B}, q_{G}\right)=\left(q_{G}-q_{B}\right) \frac{\left(2 q_{G}\left(\Theta+\Theta \tau+2\left(\gamma_{G}+\tau \gamma_{B}\right)\right)-\left(q_{G}+q_{B}\right)\left(\tau \gamma_{G}+\gamma_{B}\right)\right)^{2}}{\left(4 q_{G}-q_{B}\right)^{2}(\tau+1)} \\
& \pi_{B}^{*}\left(q_{B}, q_{G}\right)=q_{G}\left(q_{G}-q_{B}\right) \frac{\left(q_{B}\left(\Theta+\Theta \tau+2 \gamma_{G}+2 \tau \gamma_{B}\right)-2\left(q_{G}+q_{B}\right)\left(\tau \gamma_{G}+\gamma_{B}\right)\right)^{2}}{q_{B}\left(4 q_{G}-q_{B}\right)^{2}(\tau+1)}
\end{aligned}
$$

Since both the price and the market share of firm G are higher than those of firm B, profit of the high quality firm are larger than profit of low quality firm.

\section{Quality Choice stage}

- Choice of $q_{G}^{*}$

Taking the derivative of $\pi_{G}^{*}\left(q_{G}, q_{B}\right)$ with respect to $q_{G}$, we find

$$
\begin{aligned}
\partial \pi_{G}^{*}\left(q_{B}, q_{G}\right) / \partial q_{G}= & (\tau+1)\left(2 \Theta q_{G}+\left(3 q_{G}-q_{B}\right) \gamma_{G}\right) * \\
& * \frac{q_{G}\left(2\left(4 \Theta q_{G}-3 \Theta q_{B}\right)+\gamma_{G}\left(12 q_{G}-5 q_{B}\right)\right)+\left(4 \Theta-\gamma_{G}\right) q_{B}^{2}}{\left(4 q_{G}-q_{B}\right)^{3}}
\end{aligned}
$$

which is positively signed for $q_{G}>q_{B}$ and $\Theta>\gamma_{G}$ for positivity of prices. It follows that under country-specific relative preferences, for any given level of the trade costs, the firm producing the high quality firm selects the highest possible level of quality $\bar{q}$. 
- Choice of $q_{B}^{*}$

Taking the derivative of $\pi_{B}^{*}\left(q_{B}, q_{G}\right)$ with respect to $q_{B}$, we find

$$
\begin{aligned}
\frac{\partial \pi_{B}^{*}\left(q_{B}, q_{G}\right)}{\partial q_{B}}= & q_{G}^{2} \underbrace{\left(\begin{array}{c}
\Theta q_{B}-2 \gamma_{B} q_{G}+2 \gamma_{G} q_{B}-2 \gamma_{B} q_{B}+\Theta \tau q_{B} \\
-2 \tau \gamma_{G} q_{G}-2 \tau \gamma_{G} q_{B}+2 \tau \gamma_{B} q_{B}
\end{array}\right)}_{\text {positive if prices are positive }} * \\
& * \frac{\left.\begin{array}{c}
-7 \Theta q_{B}^{2}+8 \gamma_{B} q_{G}^{2}-14 \gamma_{G} q_{B}^{2}+18 \gamma_{B} q_{B}^{2}-7 \Theta \tau q_{B}^{2} \\
+8 \tau \gamma_{G} q_{G}^{2}+18 \tau \gamma_{G} q_{B}^{2}-14 \tau \gamma_{B} q_{B}^{2}+4 \Theta q_{G} q_{B}+ \\
8 \gamma_{G} q_{G} q_{B}-14 \gamma_{B} q_{G} q_{B}+4 \Theta \tau q_{G} q_{B}-14 \tau \gamma_{G} q_{G} q_{B}+8 \tau \gamma_{B} q_{G} q_{B}
\end{array}\right)}{\underbrace{\text { parabola in } q_{B}}_{q_{B}^{2}\left(4 q_{G}-q_{B}\right)^{3}(\tau+1)}}
\end{aligned}
$$

The parabola in $q_{B}$ rewrites as

$$
\begin{aligned}
& \left(\left(18 \gamma_{G}-7 \Theta-14 \gamma_{B}\right) \tau+\left(18 \gamma_{B}-14 \gamma_{G}-7 \Theta\right)\right) q_{B}^{2}+ \\
& \left(4 \Theta q_{G}+8 \gamma_{G} q_{G}-14 \gamma_{B} q_{G}+4 \Theta \tau q_{G}-14 \tau \gamma_{G} q_{G}+8 \tau \gamma_{B} q_{G}\right) q_{B}+ \\
& +\left(8 \gamma_{B} q_{G}^{2}+8 \tau \gamma_{G} q_{G}^{2}\right)
\end{aligned}
$$

First, under the positivity of $p_{B}^{*}$, the expression $\left(4 \Theta q_{H}+8 \gamma_{G} q_{H}-14 \gamma_{B} q_{H}+4 \Theta \tau q_{G}-14 \tau \gamma_{G} q_{G}+8 \tau \gamma_{B} q_{G}\right)$ is positive. It remains to analyse the concavity of the parabola, namely the sign of $\left(\left(18 \gamma_{G}-7 \Theta-14 \gamma_{B}\right) \tau+\left(18 \gamma_{B}-\right.\right.$ Rename $\left(18 \gamma_{G}-7 \Theta-14 \gamma_{B}\right) \equiv A$ and $\left(18 \gamma_{B}-14 \gamma_{G}-7 \Theta\right) \equiv B$ with:

- $A<0$ iff $\gamma_{G}<\bar{\gamma}_{G}$ where $\bar{\gamma}_{G} \equiv \frac{7}{18} \Theta+\frac{7}{9} \gamma_{2}$

- $B<0$ iff $\gamma_{G}>\breve{\gamma}_{G}$ where $\breve{\gamma}_{G} \equiv \frac{9}{7} \gamma_{2}-\frac{1}{2} \Theta$ and $\bar{\gamma}_{G}>\breve{\gamma}_{G}$.

Solve $A \tau+B=0$ and denote the solution in $\tau$ by $\breve{\tau} \equiv-\frac{7 \Theta+14 \gamma_{G}-18 \gamma_{B}}{7 \Theta-18 \gamma_{G}+14 \gamma_{B}}$. This is a threshold on $\tau$ that is admissible and meaningful if it assumes values in the interval: $0<-\frac{7 \Theta+14 \gamma_{G}-18 \gamma_{B}}{7 \Theta-18 \gamma_{G}+14 \gamma_{B}}<1$. Two scenarios may appear:

1. For A and B negative, i.e. for $\breve{\gamma}_{G}<\gamma_{G}<\bar{\gamma}_{G}$, we have that $\breve{\tau}>1$. Hence, for $\breve{\gamma}_{G}<\gamma_{G}<\bar{\gamma}_{G}$ and any value of $\tau$, the parabola is concave.

2. For A positive and B negative, and for A negative and B positive, there may exist a threshold value of the transportation cost for which the parabola is convex or concave.

Given $\breve{\tau} \equiv-\frac{7 \Theta+14 \gamma_{G}-18 \gamma_{B}}{7 \Theta-18 \gamma_{G}+14 \gamma_{B}}$, since $\breve{\tau}>1$ both for $\gamma_{G}<\breve{\gamma}_{G}$ and for $\gamma_{G}>\breve{\gamma}_{G}$, the parabola is always convex in the former case $\gamma_{G}<\breve{\gamma}_{G}$, by contrast, in the latter case $\gamma_{G}>\breve{\gamma}_{G}$ the parabola is always concave.

To conclude, for $\gamma_{G}<\breve{\gamma}_{G}$, the whole parabola in (3) is positively signed, hence $\frac{\partial \pi_{B}^{*}\left(q_{B}, q_{G}\right)}{\partial q_{B}}>0$. Therefore, for this range of values of $\gamma_{G}$, we have a corner solution with $q_{B}^{*}=q_{B}^{\max }$, being $q_{B}^{\max }$ the 
highest achievable quality by the brown producer. In order to preserve the essence of a vertically differentiated duopoly, we assume that $q_{B}^{\max }<q_{G}^{*}$.

Instead, for $\gamma_{G}>\breve{\gamma}_{G}$, we find that the parabola is positive for $q_{B}=0$ implying an interior solution strictly smaller than $q_{B}^{\max }$.

\section{References}

[1] Abbott A., Nandeibam S. and L. O'Shea (2013). Recycling: social norms and warmglow revisited, Ecological Economics, 90, 10-18.

[2] Akerlof, G. (1997). Social distance and social decisions, Econometrica 65, 1005-1027.

[3] Alexopoulos, M. and S. Sapp (2006). Exploring the behavior of economic agents: the role of relative preferences, Economics Bulletin 12(2), 1-7.

[4] Alpizar F. and E. Gsottbauer (2015). Reputation and household recycling practices: field experiments in Costa Rica, Ecological Economics, 120, 366-375.

[5] André, F. J., González, P., and N. Porteiro (2009). Strategic quality competition and the Porter Hypothesis. Journal of Environmental Economics and Management, 57(2), 182-194.

[6] Antweiler, W., B.R. Copeland and M.S. Taylor (2001). Is Free Trade Good for the Environment?, American Economic Review, 91, 877-908.

[7] Baldwin, R., and J. Harrigan (2011). Zeros, quality, and space: Trade theory and trade evidence, American Economic Journal: Microeconomics, 3(2), 60-88.

[8] Ben Elhadj N. and O. Tarola (2015). Relative quality (dis)utility in a vertically differentiated oligopoly with an environemntal externality, Environment and Development Economics, 20 (3), 349-373.

[9] Beshears, J., Choi, J. J., Laibson, D., Madrian, B. C., and , K. L. Milkman (2015). The effect of providing peer information on retirement savings decisions, The Journal of Finance, 70(3), 1161-1201.

[10] Brekke, K.A., Kverndokk, S. and K. Nyborg (2003). An Economic Model of Moral Motivation, Journal of Public Economics, 87 (9-10), 1967-1983.

[11] Brekke, K. A., Kipperberg, G., and K. Nyborg (2010). Social interaction in responsibility ascription: the case of household recycling, Land Economics, 86(4), 766-784.

[12] Bursztyn, L., Ederer, F., Ferman, B., and N. Yuchtman (2014). Understanding mechanisms underlying peer effects: Evidence from a field experiment on financial decisions, Econometrica, $82(4), 1273-1301$. 
[13] Cabrales, A., and M. Motta (2001). Country asymmetries, endogenous product choice and the timing of trade liberalization, European Economic Review, 45(1), 87-107.

[14] Carlsson, F., Garcia, J. and Å. Löfgren (2010). Conformity and the Demand for Environmental Goods, Environmental and Resource Economics, 47 (3), 407-421.

[15] Cecere G., Mancinelli S. and M. Mazzanti (2014). Waste prevention and social preferences: the role of intrinsic and extrinsic motivations, Ecological Economics, 107, 163-176.

[16] Conrad K. (2005). Price Competition and Product Differentiation When Consumers Care for the Environment, Environmental and Resource Economics, 31 (1), 1-19.

[17] Copeland B.R. and M.R. Taylor (1994). North-South trade and the environment, Quarterly Journal of Economics 10, 755-787

[18] Copeland B.R. and M.R. Taylor. (2003), Trade and the Environment: Theory and Evidence, Princeton University Press.

[19] Czajkowski M., Hanley N.,and K. Nyborg (2015), Social norms, morals and selfinterest as determinants of pro-environmental behaviours: the case of household recycling, Environmental and Resource Economics, DOI: 10.1007/s10640-015- 9964-3.

[20] Deltas, G., Harrington, D. R. and M. Khanna (2013). Oligopolies with (Somewhat) Environmentally Conscious Consumers: Market Equilibrium and Regulatory Intervention, Journal of Economics and Management Strategy, 22 (3), 640-667.

[21] Dietz, T., Fitzgerald, A., and R. Shwom (2005). Environmental Values, Annual Review of Environment and Resources, 30, 335-372.

[22] Dohmen, T., A. Falk, K. Fliessbach, U. Sunde, and B. Weber (2011). Relative versus absolute income, joy of winning, and gender: Brain imaging evidence. Journal of Public Economics $95(3), 279-285$.

[23] Dunlap R. and A. Metig (1995). Global concern for the environment: is affluence a prerequisite?, Journal of Social Issues, 51.

[24] Eriksson C. (2004). Can green consumerism replace environmental regulation? A differentiated product example. Resource and Energy Economics, 26, 281-293.

[25] European Commission (2013). Attitudes of europeans towards building the single market for green products. Flash Eurobarometer 367.

[26] Fajgelbaum, P., Grossman, G. M., and E. Helpman (2011). Income Distribution, Product Quality, and International Trade, Journal of Political Economy, 119(4), 721-765.

[27] Flam, H., and Helpman, E. (1987). Vertical product differentiation and North-South trade, American Economic Review, 810-822. 
[28] Fliessbach, K., B. Weber, P. Trautner, T. J. Dohmen, U. Sunde, C. E. Elger, and A. Falk (2007). Social comparison affects reward-related brain activity in the human ventral striatum, Science. 318.

[29] Gabszewicz, J. J., and Thisse, J. F. (1979). Price competition, quality and income disparities, Journal of Economic Theory, 20(3), 340-359.

[30] Gabszewicz, J. J., M. Marini and S. Zanaj, (2017). Random encounters and information diffusion about markets. CREA discussion papers, 2017-24.

[31] Garcìa-Gallego A. and Georgantizis N. (2009). Market Effect of Changes in Consumers Social Responsibility, Journal of Economics and Management Strategy 18(1), 235-262.

[32] Hage O., Soderholm P., Berglund C., (2009). Norms and economic motivation in household recycling: empirical evidence for Sweden, Resources, Conservation and Recycling, 53, 155-165.

[33] Hallak, J. C., and Schott, P. K. (2011). Estimating cross-country differences in product quality, Quarterly Journal of Economics, 126(1), 417-474.

[34] Heffiner R., Kurani K.S. and Turrentine T.S. (2007). Symbolism in California: Early market for Hybrid Electric Vehicles, Transportation Research Part D, 12, 396-413.

[35] Herguera, I., Kujal, P., and E. Petrakis (2000). Quantity restrictions and endogenous quality choice, International Journal of Industrial Organization, 18(8), 1259-1277.

[36] Hummels, D., and P. J. Klenow (2005). The variety and quality of a nation's exports, American Economic Review, 95(3), 704-723.

[37] Khandelwal, A. (2010). The long and short (of) quality ladders, The Review of Economic Studies, 77(4), 1450-1476.

[38] Krugman, P. R. (1989). Industrial organization and international trade. Handbook of industrial organization, 2, 1179-1223.

[39] Linder, S. B. (1961). An essay on trade and transformation. Wiley.

[40] Litina A., Moriconi S. and S. Zanaj (2016). The Cultural Transmission of Environmental Value: A Comparative Approach, World Development, 84(C), 131-148.

[41] Lombardini-Riipinen C. (2005). Optimal Tax Policy under Environmental Quality Competition Environmental and Resource Economics, 32 (3), 317-336.

[42] Mantovani, A., Tarola, O., and C. Vergari (2017). End-of-pipe or cleaner production? How to go green in presence of income inequality and pro-environmental behavior, Journal of Cleaner Production, (160), 71-82. 
[43] Moraga-Gonzalez, J. L. and N. Padron-Fumero (2002). Environmental Policy in a Green Market, Environmental and Resource Economics, 22 (3), pp. 419-447.

[44] Motta, M. and Thisse, J. F. (1993). Minimum Quality Standard as an Environmental Policy: Home country and International Effects. Nota di Lavoro 20, Fondazione Eni Enrico Mattei.

[45] Murphy, K. M., and Shleifer, A. (1997). Quality and trade, Journal of Development Economics, $53(1), 1-15$.

[46] Mussa, M., and S. Rosen (1978). Monopoly and product quality, Journal of Economic Theory, 18(2), 301-317.

[47] Nyborg, K., Howarth R.B. and K.A. Brekke (2006). Green Consumers and Public Policy: On Socially Contingent Moral Motivation, Resource and Energy Economics, 28 (4), pp. 351-366

[48] Ostrom, E. (2000). Collective Action and the Evolution of Social Norms, Journal of Economic Perspectives, 14 (3), pp. 137-158.

[49] Owen, A.L. and J. Videras (2006). Civic cooperation, proenvironment attitudes, and behavioral intentions, Ecological Economics, 58 (4), pp. 814-829.

[50] Owen A. L. and J. R. Videras (2007). Culture and public goods: the case of religion and the voluntary provision of environmental quality, Journal of Environmental Economics and Management, 54, 162-180.

[51] Picard P. M. and A. Tampieri (2016). Income Effects and Vertical Differentiation in International Trade, CREA Discussion Paper Series 16-05, Center for Research in Economic Analysis, University of Luxembourg.

[52] Riechmann, T. (2006). Mixed motives in a Cournot game, Economics Bulletin 4(29), 1-8.

[53] Rodriguez-Ibeas R. (2007). Environmental Product differentiation and Environmental Awareness, Environmental and Resource Economics 36, 237-254.

[54] Sanin, M. E., and S. Zanaj (2011). A note on clean technology adoption and its influence on tradeable emission permits prices, Environmental and Resource Economics, 48(4), 561-567.

[55] Schünemann J and T. Trimborn (2017). "Boosting taxes for boasting about houses: Status concerns in the housing market," ECON WPS - Vienna University of Technology Working Papers in Economic Theory and Policy 05/2017, Vienna University of Technology, Institute for Mathematical Methods in Economics, Research Group Economics (ECON).

[56] Sexton, S. E., and A. L Sexton (2014). Conspicuous conservation: The Prius halo and willingness to pay for environmental bona fides, Journal of Environmental Economics and Management, 67(3), 303-317. 
[57] Steg, L., and J. I. M. de Groot (2012). Environmental values. In S. Clayton (Ed.), The Oxford Handbook of Environmental and Conservation Psychology (81-92). New York: Oxford University Press.

[58] Stern P.C. (2000). Toward a Coherent Theory of Environmentally Significant Behavior, Journal of Social Issues , 56 (3), 407-424.

[59] Torgler B. and García-Valiňas (2007), The determinants of individuals' attitudes towards preventing environmental damage, Ecological Economics, 63, 536-552.

[60] Van den Bergh J.C.J.M., (2008), Environmental regulation of households: an empirical review of economic and psychological factors, Ecological Economics, 66, 559-574.

[61] Veblen, T. (1899). Theory of the Leisure Class: An Economic Study in the Evolution of Institutions. New York: Macmillan.

[62] Verhoogen, E. A. (2008). Trade, quality upgrading, and wage inequality in the Mexican manufacturing sector, Quarterly Journal of Economics, 123(2), 489-530.

[63] Videras, J., Owen, A. L., Conover, E., and S. Wu (2012). The influence of social relationships on pro-environment behaviors, Journal of Environmental Economics and Management, 63(1), $35-50$.

[64] Welsch, H., and J. Kühling (2009). Determinants of pro-environmental consumption: The role of reference groups and routine behavior, Ecological Economics, 69(1), 166-176. 